\title{
POLA SEBARAN KONSENTRASI OKSIGEN TERLARUT PADA PARIT TOKAYA
}

\author{
Eva Pramuni Oktaviani Sitanggang ${ }^{1}$, Rizki Purnaini ${ }^{2}$, Kiki Prio Utomo ${ }^{3}$ \\ Program Studi Teknik Lingkungan, Universitas Tanjungpura, Pontianak \\ Email : evapramuni@yahoo.com
}

\begin{abstract}
ABSTRAK
Saluran drainase Parit Tokaya memiliki panjang $\pm 6,7 \mathrm{~km}$ dan mengalir di Kecamatan Pontianak Selatan. Saluran drainase ini berfungsi mengalirkan air hujan serta air limbah dari kegiatan rumah tangga dan air limbah dari kegiatan lain yang berada di sepanjang alirannya. Penelitian ini mempelajari kualitas air dan profil sebaran konsentrasi oksigen terlarut pada saluran tersebut.

Berdasarkan Keputusan Menteri Lingkungan Hidup Nomor 110 Tahun 2003, metode yang digunakan untuk menggambarkan profil sebaran konsentrasi oksigen terlarut di saluran adalah model Streeter - Phelps. Pengambilan sampel air dilakukan di 11 titik sepanjang saluran dengan mempertimbangkan tata guna lahan serta kondisi pasang dan surut. Pengujian sampel air dilakukan untuk parameter suhu, pH, kekeruhan, Dissolved Oxygen (DO) dan Biochemical Oxygen Demand (BOD). Perubahan konsentrasi oksigen terlarut dianalisa terhadap parameter DO dan BOD berdasarkan hubungannya dengan perbedaan tata guna lahan di sepanjang daerah aliran.

Model matematika dengan metode Streeter-Phelps kemudian dibandingkan dengan data lapangan dan memberikan nilai regresi linear mendekati 1 pada kondisi pasang dan surut. Ini menunjukkan model matematika Streeter - Phelps dapat digunakan untuk menggambarkan profil sebaran konsentrasi oksigen terlarut di saluran pada kondisi pasang dan surut. Profil sebaran konsentrasi oksigen terlarut yang dihasilkan pada kondisi surut menunjukkan bahwa saluran tidak mampu memulihkan kembali konsentrasi oksigen terlarutnya. Sedangkan pada kondisi pasang, walaupun sempat terjadi penurunan konsentrasi oksigen terlarut namun saluran dapat memulihkan kembali konsentrasi oksigen terlarutnya.
\end{abstract}

Kata kunci : Parit Tokaya, model Streeter-Phelps, konsentrasi oksigen terlarut

\begin{abstract}
Parit Tokaya is one of the main drainage channels in Pontianak that receiving rain water and wastewater from human settlement along its reach. It is important to investigate its water quality. One of the water quality parameter that is investigated in this paper is Dissolved Oxygen (DO) concentration profile along the channel. To study DO concentration profile in a channel, one can refer to PP No. 110 Tahun 2003. The proposed method according to the decree is Streeter - Phelps Method. Water samples from 11 points along Parit Tokaya channel are collected on May 22 ${ }^{\text {th }}, 2012$. Sampling point were chosen regarding land use. Sampling period is determined by tidal period that influencing water flows, water level and water quality in the channel. Water velocity and five other parameters are measured: temperature, $\mathrm{pH}$, turbidity, DO and biochemical oxygen demand (BOD). Result from field measurement then compared to the mathematical models based on Streeter-Phelps Method. Results shows regression values for high tide and low tide are close to 1 which mean the Streeter - Phelps Method as a mathematical model can be used to describe DO concentration profile in Parit Tokaya channel. Results also indicated that Parit Tokaya channel unable to recover DO concentration during low tide. While during high tide, it could recover its DO concentration through a self-purification process.
\end{abstract}

Keywords : Parit Tokaya, Streeter-Phelps model, dissolved oxygen concentration

\section{Pendahuluan}

Parit Tokaya merupakan salah satu dari 25 saluran drainase primer di Kota Pontianak. Parit Tokaya memiliki panjang $\pm 6,7 \mathrm{~km}$ dan mengalir melalui Kecamatan Pontianak Selatan. Saluran drainase ini memiliki peran yang cukup penting bagi wilayah Kecamatan Pontianak Selatan karena selain berfungsi menampung dan mengalirkan air hujan, saluran ini juga berfungsi menampung dan mengalirkan air limbah dari kegiatan rumah tangga yang dihasilkan oleh masyarakat sekitar serta air 
limbah dari kegiatan lain yang berada di sepanjang alirannya. Berdasarkan pengamatan yang telah dilakukan di lapangan, pencemaran lingkungan yang terjadi pada saluran drainase ini semakin tampak jelas, badan saluran drainase dipenuhi dengan timbunan sampah, terjadi pendangkalan akibat adanya sampah dan lumpur di dasar saluran serta air yang berwarna kehitaman dan berbau menyengat.

Salah satu parameter kualitas air yang menarik untuk dipelajari akibat pembuangan limbah rumah tangga secara terus - menerus pada perairan ialah konsentrasi oksigen terlarut. Konsentrasi oksigen terlarut menjadi menarik untuk dipelajari karena oksigen terlarut dibutuhkan oleh semua makhluk hidup dalam proses respirasi. Selain itu, oksigen terlarut dalam perairan juga dibutuhkan dalan proses penguraian bahan organik. Proses penguraian bahan organik yang dilakukan oleh mikroorganisme pada perairan dapat membantu mengurangi beban pencemaran di perairan tersebut sehingga keberadaan konsentrasi oksigen terlarut merupakan faktor penting di perairan.

Perubahan konsentrasi oksigen terlarut pada perairan dipengaruhi oleh proses pengurangan oksigen terlarut (deoksigenasi) akibat aktivitas bakteri dalam menguraikan bahan organik dalam air serta proses peningkatan oksigen terlarut (reaerasi) yang disebabkan turbulensi aliran sungai. Perubahan konsentrasi oksigen terlarut dapat digunakan untuk menggambarkan kondisi kualitas air pada perairan sebagai saluran drainase penerima limbah domestik dan limpasan permukaan. Selain itu, dapat dianalisa kemungkinan penyebab penurunan kondisi kualitas air tersebut sebagai bahan pertimbangan dalam mengendalikan pencemaran yang terjadi di saluran drainase Parit Tokaya.

Tujuan dari penelitian ini adalah mengetahui kondisi kualitas air di saluran drainase Parit Tokaya serta hubungannya terhadap konsentrasi oksigen terlarut dan melakukan penerapan model StreeterPhelps di sepanjang aliran Parit Tokaya.

\section{Metodologi Penelitian}

Penelitian dilakukan selama lima (5) bulan, yang dimulai dari bulan Mei 2012 hingga September 2012. Penelitian ini dilakukan dalam 4 tahap yang meliputi :

1. Persiapan pendahuluan yang terdiri dari studi pustaka mengenai objek yang diteliti serta observasi awal untuk mengetahui kondisi lokasi penelitian.

2. Pengumpulan data berupa data sekunder dan data primer. Data sekunder yang dikumpulkan dalam penelitian ini ialah data berupa dokumen hasil penelitian pihak lain maupun literatur lain yang didapatkan melalui instansi-instansi yang memiliki kaitan dengan permasalahan yang diteliti sedangkan pengumpulan data primer berupa data struktur dan kondisi saluran, dimensi saluran, kecepatan aliran pada saluran serta kualitas air saluran drainase Parit Tokaya. Pengambilan sampel air dilakukan di 11 titik di sepanjang aliran Parit Tokaya dengan mempertimbangkan tata guna lahan serta kondisi pasang dan surut yang mengacu pada kondisi pasang dan surut di Sungai Kapuas Kecil. Lokasi pengambilan sampel air dapat dilihat pada Gambar 1. Pengujian sampel air dilakukan untuk parameter suhu, pH, kekeruhan, Dissolved Oxygen (DO) dan Biochemical Oxygen Demand (BOD). 


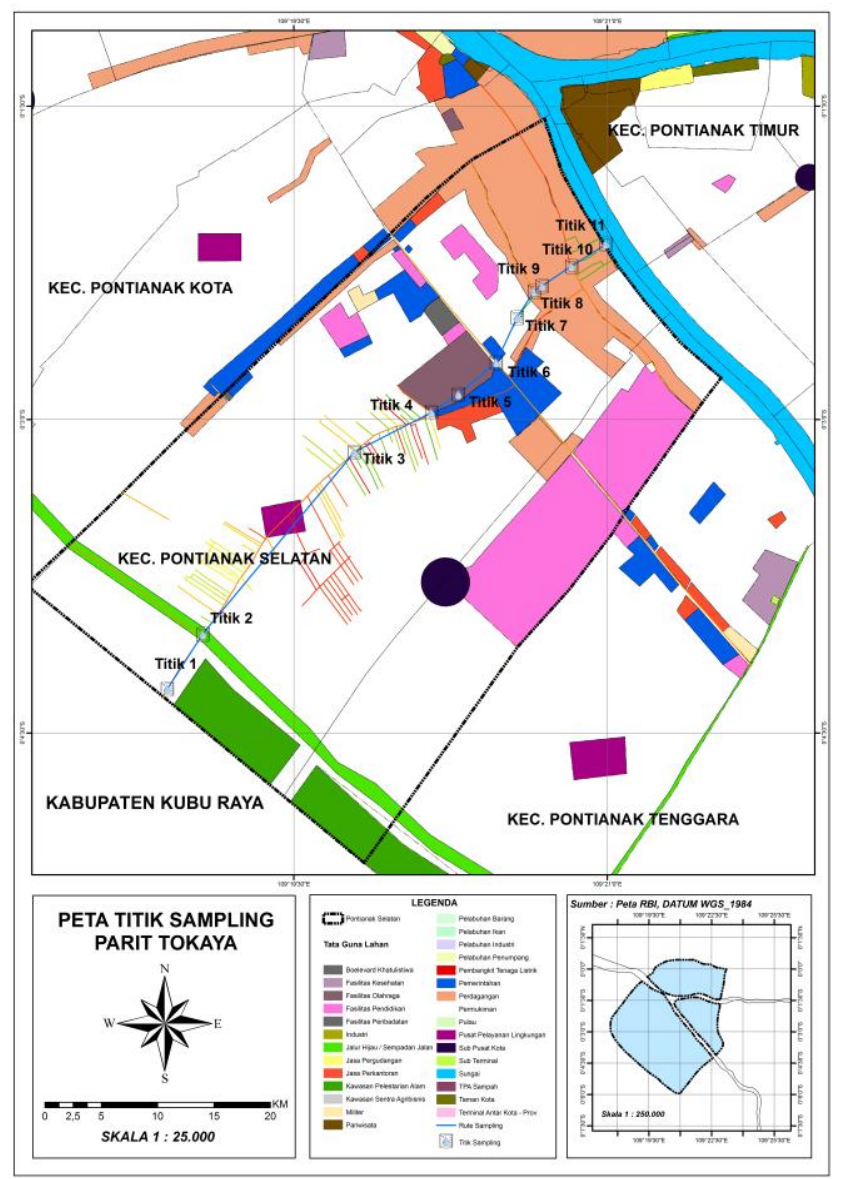

Gambar 1. Lokasi pengambilan sampel air pada Parit Tokaya

3. Analisa data kualitas air. Proses analisa data kualitas air dilakukan untuk masing-masing parameter dengan membandingkannya dengan klasifikasi mutu air menurut Peraturan Pemerintah Nomor 82 Tahun 2001 serta Peraturan Menteri Kesehatan Republik Indonesia tanggal 3 September 1990 tentang syarat-syarat dan pengawasan kualitas air bagian daftar persyaratan kualitas air bersih. Selain itu juga dilakukan analisa untuk melihat pengaruh parameter suhu, kekeruhan dan Biochemical Oxygen Demand (BOD) terhadap konsentrasi oksigen terlarut pada Parit Tokaya.

4. Penerapan model matematika Steeter-Phelps. Mengacu kepada Keputusan Menteri Negara Lingkungan Hidup Nomor 110 tahun 2003, salah satu metode yang dapat digunakan untuk mengetahui nilai defisit oksigen serta menggambarkan pola sebaran konsentrasi oksigen terlarut di perairan adalah model Streeter-Phelps. Bentuk persamaan model Streeter-Phelps dapat dilihat pada Persamaan 1 (Davis dan Cornwell, 1991).

$$
\mathrm{D}=\frac{\mathrm{k}_{\mathrm{d}} \mathrm{L}_{\mathrm{a}}}{\mathrm{k}_{\mathrm{r}}-\mathrm{k}_{\mathrm{d}}}\left(\mathrm{e}^{-\mathrm{k}_{\mathrm{d}} \frac{\mathrm{x}}{\mathrm{v}}}-\mathrm{e}^{-\mathrm{k}_{\mathrm{r}} \frac{\mathrm{x}}{\mathrm{v}}}\right)+\mathrm{D}_{\mathrm{a}}\left(\mathrm{e}^{-\mathrm{k}_{\mathrm{r}} \frac{\mathrm{x}}{\mathrm{v}}}\right)
$$

dimana :

$\mathrm{D}=$ defisit oksigen pada badan air setelah digunakan untuk penguraian bahan organik $(\mathrm{mg} / \mathrm{l})$

$\mathrm{L}_{\mathrm{a}} \quad=$ konsentrasi BOD pada badan air $(\mathrm{mg} / \mathrm{l})$

$\mathrm{k}_{\mathrm{d}} \quad=$ konstanta laju penguraian bahan organik oleh mikroorganisme (I/hari)

$D_{a}=$ defisit oksigen pada badan air $(\mathrm{mg} / \mathrm{l})$

$\mathrm{k}_{\mathrm{r}} \quad=$ konstanta laju reaerasi pada badan air (I/hari)

$\mathrm{x}=$ jarak titik pengamatan terhadap titik sebelumnya $(\mathrm{km})$

$\mathrm{v} \quad=$ kecepatan pengaliran air $(\mathrm{m} / \mathrm{hari})$ 


\section{Hasil dan Analisis}

\section{A. Kualitas Air}

Pengambilan sampel untuk mengetahui kualitas air pada saluran drainase Parit Tokaya dilakukan pada tanggal 22 Mei 2012 untuk kondisi pasang dan surut yang mengacu pada peramalan pasang surut Sungai Kapuas Kecil menurut data TNI Angkatan Laut. Untuk kondisi surut, diambil pada pukul 09.00 - 11.00 sedangkan untuk kondisi pasang diambil pada pukul 18.00 - 19.00. Proses analisa kualitas air dilakukan untuk parameter suhu, pH, kekeruhan, BOD dan DO. Analisa parameter suhu, $\mathrm{pH}, \mathrm{DO}$ dan BOD dilakukan dengan membandingkan hasil yang didapat dengan klasifikasi mutu air menurut Peraturan Pemerintah Nomor 82 Tahun 2001, sedangkan untuk analisa parameter kekeruhan dilakukan dengan membandingkan hasil yang didapat dengan Peraturan Menteri Kesehatan Republik Indonesia tanggal 3 September 1990 tentang syarat-syarat dan pengawasan kualitas air bagian daftar persyaratan kualitas air bersih. Hal ini dilakukan agar dapat diketahui kualitas air pada saluran drainase Parit Tokaya berdasarkan klasifikasi mutu air. Kondisi kualitas air pada saluran drainase Parit Tokaya dapat dilihat pada Tabel 1. 
Tabel 1. Kondisi Kualitas Air pada Saluran Drainase Parit Tokaya

\begin{tabular}{|c|c|c|c|c|c|c|c|c|c|c|c|}
\hline \multirow{2}{*}{$\begin{array}{l}\text { Jarak } \\
(\mathbf{k m})\end{array}$} & \multirow{2}{*}{ Lokasi Penelitian } & \multicolumn{2}{|c|}{ Suhu $\left({ }^{\circ} \mathrm{C}\right)$} & \multicolumn{2}{|c|}{ pH } & \multicolumn{2}{|c|}{ Kekeruhan (NTU) } & \multicolumn{2}{|c|}{ BOD (mg/I) } & \multicolumn{2}{|c|}{$\mathrm{DO}(\mathrm{mg} / \mathrm{l})$} \\
\hline & & Surut & Pasang & Surut & Pasang & Surut & Pasang & Surut & Pasang & Surut & Pasang \\
\hline 0,00 & Pintu air di Jalan Purnama 2 & 26,0 & 25,0 & 4,0 & 4,7 & 10,84 & 11,61 & 8,14 & 4,75 & 4,06 & 3,38 \\
\hline 1,45 & Persimpangan Jalan Harapan Jaya & 29,0 & 26,0 & 3,6 & 4,6 & 10,67 & 10,87 & 3,39 & 5,08 & 4,74 & 2,88 \\
\hline 3,54 & Di depan Komplek Perumahan Purnama Agung 3 & 28,0 & 27,0 & 4,7 & 6,6 & 36,70 & 29,00 & 5,08 & 12,71 & 2,88 & 3,22 \\
\hline 4,35 & $\begin{array}{l}\text { Persimpangan Jalan M. Sohor, Jalan Purnama } \\
\text { dan Jalan Sutoyo }\end{array}$ & 28,0 & 27,0 & 7,6 & 6,8 & 21,30 & 27,80 & 7,63 & 6,10 & 2,88 & 2,03 \\
\hline 4,67 & Gelanggang Olahraga (GOR) & 27,0 & 27,0 & 6,1 & 6,8 & 22,30 & 23,60 & 8,14 & 9,66 & 2,71 & 1,61 \\
\hline 5,15 & Jalan Ahmad Yani & 27,0 & 27,0 & 5,9 & 6,5 & 15,70 & 28,10 & 5,42 & 7,12 & 2,71 & 3,53 \\
\hline 5,63 & Gang Syukur 5, Jalan Veteran & 27,0 & 27,0 & 5,9 & 6,1 & 22,70 & 44,30 & 5,08 & 10,17 & 2,88 & 4,91 \\
\hline 5,95 & Jalan Gajah Mada & 26,0 & 26,0 & 6,0 & 6,1 & 20,70 & 47,50 & 7,63 & 1,36 & 3,22 & 6,61 \\
\hline 6,05 & Di depan Pasar Flamboyan & 27,0 & 27,0 & 5,9 & 6,1 & 29,10 & 49,30 & 14,24 & 3,56 & 0,84 & 5,59 \\
\hline 6,37 & Jalan Tanjungpura & 27,0 & 27,0 & 6,1 & 6,0 & 25,40 & 58,10 & 30,51 & 3,08 & 1,18 & 5,76 \\
\hline 6,70 & Muara Parit Tokaya (Gg. Martapura 3) & 27,0 & 27,0 & 6,4 & 5,8 & 26,30 & 67,60 & 28,47 & 1,69 & 0,84 & 6,44 \\
\hline & Rata-rata & 27,2 & 26,6 & 5,7 & 6,0 & 21,97 & 36,16 & 11,25 & 5,93 & 2,63 & 4,18 \\
\hline
\end{tabular}


Berdasarkan hasil pada Tabel 1 yang kemudian dibandingkan dengan Peraturan Pemerintah Nomor 82 Tahun 2001 untuk parameter suhu, pH, BOD dan DO serta Peraturan Menteri Kesehatan Republik Indonesia tanggal 3 September 1990 tentang syarat-syarat dan pengawasan kualitas air bagian daftar persyaratan kualitas air bersih untuk parameter kekeruhan, diketahui bahwa rata-rata kondisi suhu pada saluran drainase Parit Tokaya masih memenuhi standar baku mutu air Kelas I, yaitu air yang peruntukannya dapat digunakan untuk air baku air minum dan peruntukan lain yang mempersyaratkan mutu air yang sama dengan kegunaan tersebut. Untuk parameter $\mathrm{pH}$, rata-rata nilai pH saluran drainase Parit Tokaya pada kondisi pasang masih memenuhi standar baku mutu air Kelas I, yaitu air yang peruntukannya dapat digunakan untuk air baku air minum dan peruntukan lain yang mempersyaratkan mutu air yang sama dengan kegunaan tersebut sedangkan rata-rata nilai $\mathrm{pH}$ saluran drainase Parit Tokaya pada kondisi surut memenuhi standar baku mutu air Kelas IV, yaitu air yang peruntukannya dapat digunakan untuk air baku air minum dan peruntukan lain yang mempersyaratkan mutu air yang sama dengan kegunaan tersebut.

Untuk rata-rata nilai kekeruhan saluran drainase Parit Tokaya pada kondisi surut masih berada di bawah baku mutu kekeruhan untuk air bersih menurut PERMENKES Republik Indonesia Nomor: 416/MENKES/PER/IX/1990 sedangkan pada kondisi pasang, nilai kekeruhan di Parit Tokaya telah melebihi baku mutu kekeruhan untuk air bersih menurut PERMENKES Republik Indonesia Nomor : 416/MENKES/PER/IX/1990. Nilai rata-rata BOD saluran drainase Parit Tokaya pada kondisi surut hanya memenuhi standar baku mutu air Kelas IV, yaitu air yang peruntukannya dapat digunakan untuk air baku air minum dan peruntukan lain yang mempersyaratkan mutu air yang sama dengan kegunaan tersebut. Sedangkan pada kondisi pasang memenuhi standar baku mutu air kelas III, yaitu air yang peruntukannya dapat digunakan untuk pembudidayaan ikan air tawar, peternakan, air untuk mengairi pertanaman, dan atau peruntukan lain yang mempersyaratkan mutu air yang sama dengan kegunaan tersebut menurut PP No. 82 Tahun 2001. Nilai rata-rata DO di Parit Tokaya pada kondisi surut hanya memenuhi standar baku mutu air Kelas IV, yaitu air yang peruntukannya dapat digunakan untuk air baku air minum dan peruntukan lain yang mempersyaratkan mutu air yang sama dengan kegunaan tersebut. Sedangkan pada kondisi pasang memenuhi standar baku mutu air kelas II yang peruntukannya dapat digunakan untuk prasarana/sarana rekreasi air, pembudidayaan ikan air tawar, peternakan, air untuk mengairi pertanaman, dan atau peruntukan lain yang mempersyaratkan mutu air yang sama dengan kegunaan tersebut menurut PP No. 82 Tahun 2001.

\section{B. Analisa Keterkaitan Perubahan Masing-masing Parameter terhadap Konsentrasi Oksigen Terlarut}

Analisa ini dilakukan untuk mengetahui pengaruh perubahan parameter suhu, kekeruhan dan Biochemical Oxygen Demand (BOD) terhadap konsentrasi oksigen terlarut pada Parit Tokaya.

\section{Keterkaitan Suhu terhadap Konsentrasi Oksigen Terlarut (DO)}

Keterkaitan antara perubahan parameter suhu terhadap konsentrasi oksigen terlarut (DO) saat surut dan pasang dapat dilihat pada Gambar 2. 


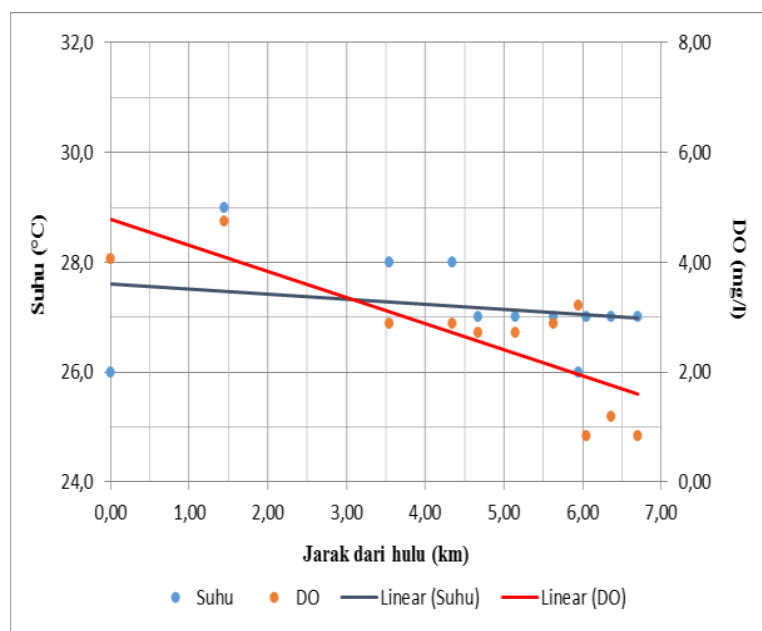

(1) Surut

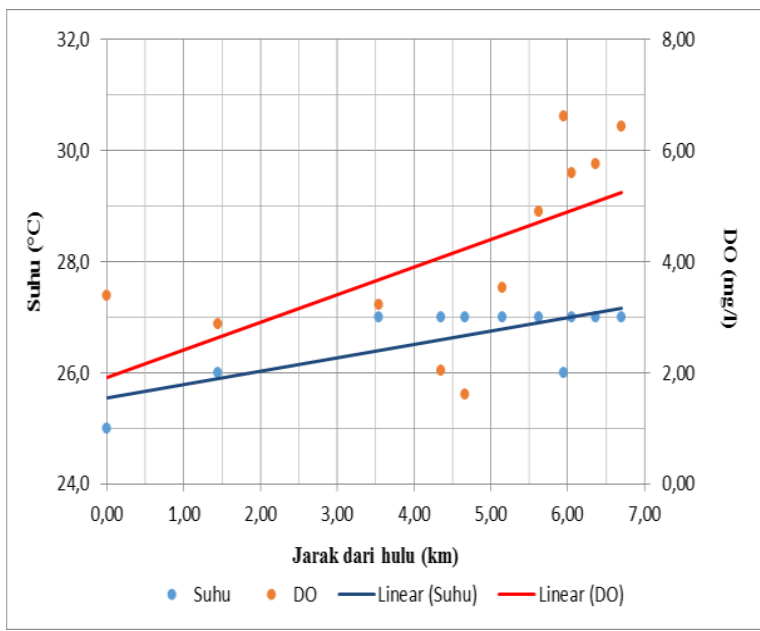

(2) Pasang

Gambar 2. Kecenderungan pengaruh perubahan suhu terhadap konsentrasi oksigen terlarut pada kondisi pasang dan surut di Parit Tokaya

Gambar 2 menunjukkan bahwa peningkatan suhu memberikan pengaruh pada penurunan konsentrasi oksigen terlarut di Parit Tokaya pada kondisi surut. Sedangkan pada kondisi pasang, perubahan suhu tidak memberikan pengaruh terhadap perubahan konsentrasi oksigen terlarut. Kemungkinan adanya faktor lain yang mengakibatkan peningkatan oksigen terlarut, seperti faktor pengenceran dan kecepatan aliran air pada kondisi pasang.

\section{Keterkaitan Kekeruhan terhadap Konsentrasi Oksigen Terlarut (DO)}

Keterkaitan antara perubahan parameter kekeruhan terhadap konsentrasi oksigen terlarut (DO) saat surut dan pasang dapat dilihat pada Gambar 3.

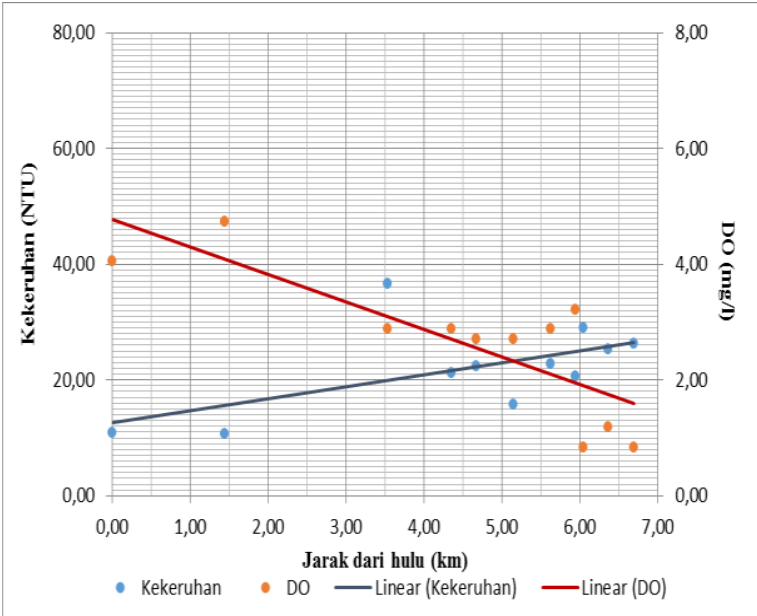

(1) Surut

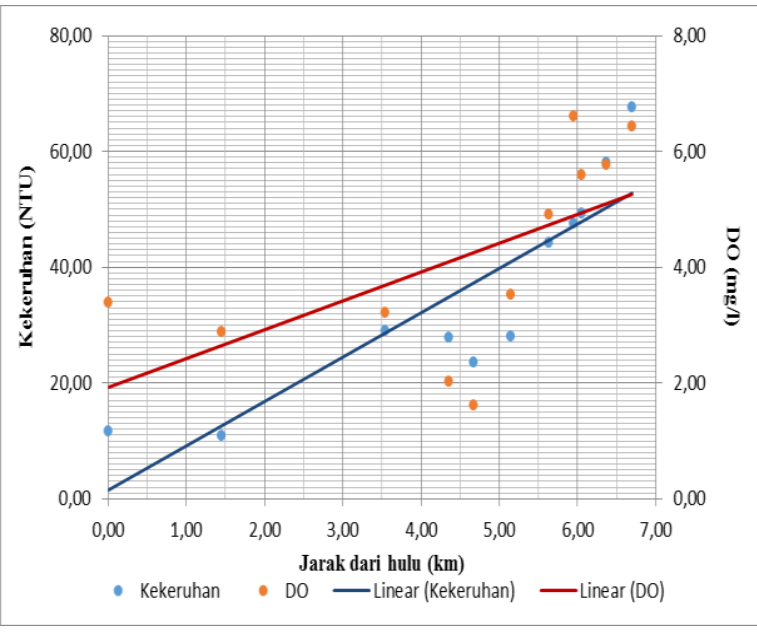

(2) Pasang

Gambar 3. Kecenderungan pengaruh perubahan kekeruhan terhadap konsentrasi oksigen terlarut pada kondisi pasang dan surut di Parit Tokaya

Gambar 3 menunjukkan bahwa peningkatan kekeruhan memberikan pengaruh pada penurunan konsentrasi oksigen terlarut di Parit Tokaya pada kondisi surut. Sedangkan pada kondisi pasang, perubahan suhu tidak memberikan pengaruh terhadap perubahan konsentrasi oksigen terlarut. Kemungkinan adanya faktor lain yang mengakibatkan peningkatan oksigen terlarut, seperti faktor pengenceran dan kecepatan aliran air pada kondisi pasang. 


\section{Keterkaitan BOD terhadap Konsentrasi Oksigen Terlarut (DO)}

Keterkaitan antara perubahan parameter BOD terhadap konsentrasi oksigen terlarut (DO) saat surut dan pasang dapat dilihat pada Gambar 4.

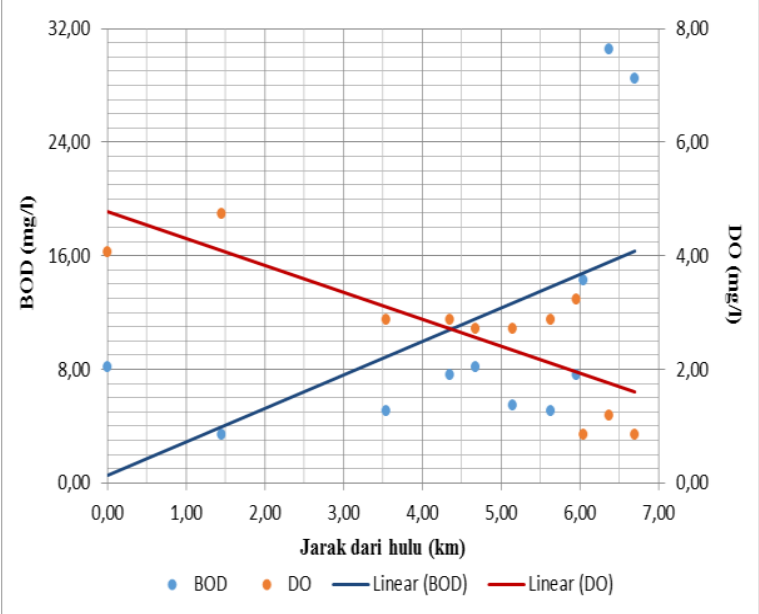

(1) Surut

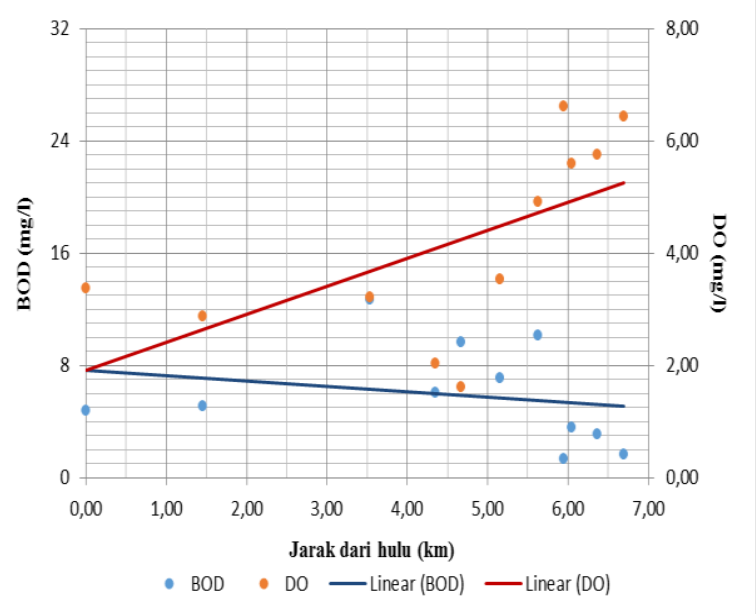

(2) Pasang

Gambar 4. Kecenderungan pengaruh perubahan parameter BOD terhadap konsentrasi oksigen terlarut pada kondisi pasang dan surut di Parit Tokaya

Gambar 4 menunjukkan bahwa peningkatan nilai BOD mengakibatkan penurunan konsentrasi oksigen terlarut di Parit Tokaya dari arah hulu kearah hilir pada kondisi surut sedangkan pada kondisi pasang, peningkatan nilai BOD kearah hulu mengakibatkan penurunan konsentrasi oksigen terlarut kearah hulu pada Parit Tokaya.

\section{Penerapan Model Matematika Streeter-Phelps}

Penerapan model matematika Streeter-Phelps dilakukan untuk menghasilkan persamaan defisit oksigen yang dapat digunakan pada sembarang titik di sepanjang aliran Parit Tokaya pada kondisi pasang dan surut. Model dasar yang digunakan dalam perhitungan ini ialah Persamaan 1.

\section{Perhitungan Defisit Oksigen dan DO Model pada Kondisi Surut}

Tabel 2. Perhitungan Defisit Oksigen dan DO Model pada Kondisi Surut

\begin{tabular}{|c|c|c|c|c|c|c|c|c|c|c|}
\hline Titik & $\begin{array}{c}\mathbf{x} \\
(\mathbf{k m})\end{array}$ & $\begin{array}{c}\mathbf{v} \\
(\mathbf{m} / \mathbf{s})\end{array}$ & $\begin{array}{c}\mathbf{h} \\
(\mathbf{m})\end{array}$ & $\begin{array}{c}\mathbf{t} \\
\left({ }^{\circ} \mathbf{C}\right)\end{array}$ & $\begin{array}{c}\mathbf{L a} \\
(\mathbf{m g} / \mathbf{l})\end{array}$ & $\begin{array}{c}\mathbf{D a} \\
(\mathbf{m g} / \mathbf{l})\end{array}$ & $\begin{array}{c}\text { Kd } \\
(/ \mathbf{h a r i})\end{array}$ & $\begin{array}{c}\mathbf{K r} \\
(/ \mathbf{h a r i})\end{array}$ & $\begin{array}{c}\mathbf{D} \\
(\mathbf{m g} / \mathbf{l})\end{array}$ & $\begin{array}{c}\text { DO } \\
\mathbf{m o d e l} \\
(\mathbf{m g} / \mathbf{l})\end{array}$ \\
\hline 1 & 0,00 & 0,04 & 0,85 & 26,0 & 8,14 & 4,05 & 1,1 & 1,1 & 4,05 & 4,06 \\
\hline 2 & 1,45 & 0,26 & 0,68 & 29,0 & 3,39 & 2,95 & 1,3 & 4,4 & 2,46 & 5,23 \\
\hline 3 & 3,54 & 0,35 & 0,75 & 28,0 & 5,08 & 4,95 & 1,2 & 4,4 & 4,03 & 3,80 \\
\hline 4 & 4,35 & 0,35 & 0,75 & 28,0 & 7,63 & 4,95 & 1,2 & 4,4 & 4,64 & 3,19 \\
\hline 5 & 4,67 & 0,10 & 0,70 & 27,0 & 8,14 & 5,26 & 1,2 & 2,5 & 5,13 & 2,84 \\
\hline 6 & 5,15 & 0,49 & 0,60 & 27,0 & 5,42 & 5,26 & 1,3 & 7,0 & 4,93 & 3,04 \\
\hline 7 & 5,63 & 0,54 & 0,70 & 27,0 & 5,08 & 5,09 & 1,2 & 5,8 & 4,85 & 3,12 \\
\hline 8 & 5,95 & 0,60 & 0,50 & 26,0 & 7,63 & 4,89 & 1,3 & 9,9 & 4,66 & 3,45 \\
\hline 9 & 6,05 & 0,51 & 1,10 & 27,0 & 14,24 & 7,13 & 1,0 & 2,9 & 7,12 & 0,85 \\
\hline 10 & 6,37 & 0,31 & 0,90 & 27,0 & 30,51 & 6,79 & 1,1 & 3,0 & 6,93 & 1,04 \\
\hline 11 & 6,70 & 0,20 & 1,50 & 27,0 & 28,47 & 7,13 & 0,9 & 1,1 & 7,43 & 0,54 \\
\hline
\end{tabular}


Berdasarkan perhitungan yang telah dilakukan juga dihasilkan persamaan defisit oksigen yang dapat digunakan pada sembarang titik di sepanjang aliran Parit Tokaya pada kondisi surut. Persamaan ini dibuat dengan merata-ratakan nilai kecepatan, koefisien reaerasi dan koefisien deoksigenasi di sepanjang aliran Parit Tokaya. Persamaan tersebut adalah sebagai berikut :

$$
\mathrm{D}=\frac{(1.16) \mathrm{L}_{\mathrm{a}}}{(4.23)-(1.16)}\left(\mathrm{e}^{-(1.16) \frac{\mathrm{x}}{0.34}}-\mathrm{e}^{-(4.23) \frac{\mathrm{x}}{0.34}}\right)+\mathrm{D}_{\mathrm{a}}\left(\mathrm{e}^{-(4.23) \frac{\mathrm{x}}{0.34}}\right)
$$

dimana :

$\mathrm{D}=$ defisit oksigen pada badan air setelah digunakan untuk penguraian bahan organik $(\mathrm{mg} / \mathrm{l})$

$\mathrm{L}_{\mathrm{a}} \quad=$ konsentrasi BOD pada badan air $(\mathrm{mg} / \mathrm{l})$

$\mathrm{D}_{\mathrm{a}} \quad$ = defisit oksigen pada badan air ( $\left.\mathrm{mg} / \mathrm{l}\right)$

$\mathrm{x} \quad=$ jarak titik pengamatan terhadap titik sebelumnya $(\mathrm{km})$

\section{Perhitungan Defisit Oksigen dan DO Model pada Kondisi Pasang}

Tabel 3. Perhitungan Defisit Oksigen dan DO Model pada Kondisi Pasang

\begin{tabular}{|c|c|c|c|c|c|c|c|c|c|c|}
\hline Titik & $\begin{array}{c}\mathbf{x} \\
(\mathbf{k m})\end{array}$ & $\begin{array}{c}\mathbf{v} \\
(\mathbf{m} / \mathbf{s})\end{array}$ & $\begin{array}{c}\mathbf{h} \\
(\mathbf{m})\end{array}$ & $\begin{array}{c}\mathbf{t} \\
\left({ }^{\circ} \mathbf{C}\right)\end{array}$ & $\begin{array}{c}\text { La } \\
(\mathbf{m g} / \mathbf{l})\end{array}$ & $\begin{array}{c}\mathbf{D a} \\
(\mathbf{m g} / \mathbf{l})\end{array}$ & $\begin{array}{c}\text { Kd } \\
(/ \text { hari })\end{array}$ & $\begin{array}{c}\mathbf{K r} \\
(/ \mathbf{h a r i})\end{array}$ & $\begin{array}{c}\mathbf{D} \\
(\mathbf{m g} / \mathbf{l})\end{array}$ & $\begin{array}{c}\text { DO } \\
\text { model } \\
(\mathbf{m g} / \mathbf{l})\end{array}$ \\
\hline 1 & 0,00 & 0,04 & 0,75 & 25,00 & 4,75 & 4,88 & 1,1 & 1,3 & 4,88 & 3,38 \\
\hline 2 & 1,45 & 0,06 & 0,90 & 26,00 & 5,08 & 5,23 & 1,0 & 1,3 & 4,69 & 3,42 \\
\hline 3 & 3,54 & 0,18 & 0,82 & 27,00 & 12,71 & 4,75 & 1,1 & 2,6 & 4,82 & 3,15 \\
\hline 4 & 4,35 & 0,21 & 1,25 & 27,00 & 6,10 & 5,94 & 0,9 & 1,5 & 5,79 & 2,18 \\
\hline 5 & 4,67 & 0,07 & 1,20 & 27,00 & 9,66 & 6,36 & 0,9 & 1,0 & 6,50 & 1,47 \\
\hline 6 & 5,15 & 0,24 & 1,15 & 27,00 & 7,12 & 4,44 & 1,0 & 1,9 & 4,41 & 3,56 \\
\hline 7 & 5,63 & 0,19 & 1,36 & 27,00 & 10,17 & 3,06 & 0,9 & 1,3 & 3,21 & 4,76 \\
\hline 8 & 5,95 & 0,17 & 1,50 & 26,00 & 1,36 & 1,50 & 0,8 & 1,0 & 1,49 & 6,62 \\
\hline 9 & 6,05 & 0,20 & 1,30 & 27,00 & 3,56 & 2,38 & 0,9 & 1,4 & 2,38 & 5,59 \\
\hline 10 & 6,37 & 0,12 & 1,68 & 27,00 & 3,08 & 2,21 & 0,8 & 0,7 & 2,24 & 5,73 \\
\hline 11 & 6,70 & 0,06 & 2,65 & 27,00 & 1,69 & 1,53 & 0,7 & 0,3 & 1,57 & 6,40 \\
\hline
\end{tabular}

Berdasarkan perhitungan yang telah dilakukan juga dihasilkan persamaan defisit oksigen yang dapat digunakan pada sembarang titik di sepanjang aliran Parit Tokaya pada kondisi pasang. Persamaan ini dibuat dengan merata-ratakan nilai kecepatan, koefisien reaerasi dan koefisien deoksigenasi di sepanjang aliran Parit Tokaya. Persamaan tersebut adalah sebagai berikut :

$$
\mathrm{D}=\frac{(0.93) \mathrm{L}_{\mathrm{a}}}{(1.30)-(0.93)}\left(\mathrm{e}^{-(0.93) \frac{\mathrm{x}}{0.14}}-\mathrm{e}^{-(1.30) \frac{\mathrm{x}}{0.14}}\right)+\mathrm{D}_{\mathrm{a}}\left(\mathrm{e}^{-(1.30) \frac{\mathrm{x}}{0.14}}\right)
$$

dimana :

$\mathrm{D} \quad=$ defisit oksigen pada badan air setelah digunakan untuk penguraian bahan organik $(\mathrm{mg} / \mathrm{l})$

$\mathrm{L}_{\mathrm{a}} \quad=$ konsentrasi BOD pada badan air $(\mathrm{mg} / \mathrm{l})$

$\mathrm{D}_{\mathrm{a}} \quad$ = defisit oksigen pada badan air ( $\left.\mathrm{mg} / \mathrm{l}\right)$

$\mathrm{x} \quad=$ jarak titik pengamatan terhadap titik sebelumnya $(\mathrm{km})$ 


\section{Kesimpulan}

1. Berdasarkan penelitian yang telah dilakukan, kondisi kualitas air serta hubungannya dengan konsentrasi oksigen terlarut pada Parit Tokaya adalah sebagai berikut :

a. Parameter suhu masih berada pada kisaran $25-29^{\circ} \mathrm{C}$ baik untuk kondisi pasang maupun kondisi surut yang masih memenuhi standar baku mutu air Kelas I menurut PP No. 82 Tahun 2001.

b. Nilai pH di sepanjang aliran Parit Tokaya yang ditinjau berada pada kondisi asam, dengan nilai $\mathrm{pH}<7$ pada kondisi pasang maupun surut. Rata-rata nilai $\mathrm{pH}$ di Parit Tokaya pada kondisi pasang memenuhi standar baku mutu air Kelas I sedangkan rata-rata nilai pH di Parit Tokaya pada kondisi surut memenuhi standar baku mutu air Kelas IV menurut PP No. 82 Tahun 2001.

c. Rata-rata nilai kekeruhan di Parit Tokaya pada kondisi surut masih berada di bawah baku mutu kekeruhan untuk air bersih menurut PERMENKES Republik Indonesia Nomor: 416/MENKES/PER/IX/1990 sedangkan pada kondisi pasang, nilai kekeruhan di Parit Tokaya telah melebihi baku mutu kekeruhan untuk air bersih menurut PERMENKES Republik Indonesia Nomor : 416/MENKES/PER/IX/1990.

d. Nilai rata-rata BOD di Parit Tokaya pada kondisi surut memenuhi standar baku mutu air Kelas IV sedangkan pada kondisi pasang memenuhi standar baku mutu air kelas III menurut PP No. 82 Tahun 2001.

e. Nilai rata-rata DO di Parit Tokaya pada kondisi surut memenuhi standar baku mutu air Kelas IV sedangkan pada kondisi pasang memenuhi standar baku mutu air kelas II menurut PP No. 82 Tahun 2001.

2. Tata guna lahan beserta aktivitas yang ada di dalamnya, saluran sekunder dan tersier yang bermuara di Parit Tokaya serta aliran air pasang dari muara Parit Tokaya mengakibatkan perubahan kualitas air di sepanjang saluran ini.

3. Penerapan model matematika Streeter-Phelps yang dilakukan pada Parit Tokaya menghasilkan persamaan defisit oksigen yang dapat digunakan pada sembarang titik di sepanjang aliran Parit Tokaya pada kondisi pasang maupun surut.

\section{Ucapan Terima Kasih}

Ucapan terima kasih saya sampaikan kepada Ibu Rizki Purnaini, ST, MT dan Bapak Kiki Prio Utomo, ST, M.Sc sebagai pembimbing utama dan pembimbing pendamping serta Bapak Dr. Ir. Johnny MTS, M.Sc serta Ibu Hj. Henny Herawati ST, MT., dan Bapak Winardi, ST, MT sebagai penguji utama dan penguji pendamping yang telah memberikan bimbingan, masukan, dan diskusi intensif khususnya mengenai isi dari skripsi ini.

\section{Referensi}

Davis, Mackenzie L and David A. Cornwell. 1991. Introduction to environmental engineering $-2^{\text {nd }}$ International edition. Singapore: McGraw-Hill.

Keputusan Menteri Negara Lingkungan Hidup Nomor 110 Tahun 2003. Tentang Pedoman Penetapan Daya Tampung Beban Pencemaran Air pada Sumber Air.

Peraturan Menteri Kesehatan Republik Indonesia Nomor: 416/MENKES/PER/IX/1990. Tentang Syarat-Syarat dan Pengawasan Kualitas Air.

Peraturan Pemerintah Republik Indonesia Nomor 82 Tahun 2001. Tentang Pengelolaan Kualitas Air dan Pengendalian Pencemaran Air. 